\title{
Autenticidad Del ARTe CUSQUEÑO DEL SIGLO XVII EN LA OBRA DE JosÉ URIEL GARCíA (1922-1925)
}

\author{
Authenticity of 17th-century Cusqueño art in the work \\ of José Uriel García (1922-1925)
}

Marco Antonio Caparó-Aragón ${ }^{1}$

\section{RESUMEN}

El artículo es una mirada a las reflexiones histórico-artísticas de José Uriel García (1894-1965) sobre el arte cusqueño, escritos entre 1922-1925. Discurso en el que prima la creación de la historia artística peruana a través de nuevos valores estéticos propuestos en la creación del objeto artístico. Su valía intenta demostrar la presencia del arte genuino en Cusco.

En este sentido, a través de la historiografía artística, se intentó tener aproximaciones importantes para explicar el desarrollo del concepto de autenticidad plástica del autor. Y, también, la relación fáctica entre obra de arte y artista, diseminadas las reproducciones artísticas.

El análisis de los resultados permitió observar los siguientes aspectos. La autenticidad del arte cusqueño del siglo XVII se manifiesta en las edificaciones de iglesias y parroquias periféricas en los barrios populares. Lo mismo para la pintura y la escultura, cuyo principio de validéz se demuestra en la deformación del estilo barroco para introducir nuevos valores estéticos, ornamentos incaicos, rostros mestizos, etc.

Palabras clave: José Uriel García, autenticidad, arte, artista, cultura.

\section{SUMMARY}

The article is a look at the historical-artistic reflections of Jose Uriel García (1894-1965) on Cusqueño art, written between 1922-1925. Speech in which the creation of Peruvian artistic history prevails through new aesthetic values proposed in the creation of the artistic object. His worth tries to demonstrate the presence of genuine art in Cusco. In this sense,

1 Licenciado en Arte. Universidad Nacional Mayor de San Marcos, Lima, Perú.

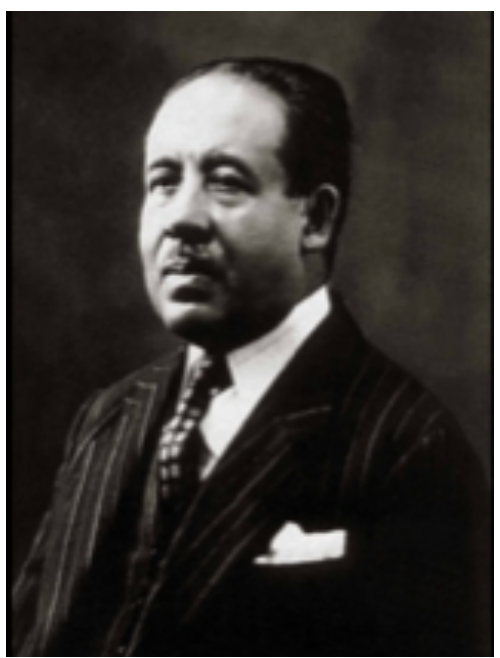

José Uriel García Ochoa (San Sebastián, Cusco, 8 de septiembre de 1894 - Miraflores, Lima, 27 de julio de 1965)

through artistic historiography, an attempt was made to have important approaches to explain the development of the concept of plastic authenticity of the author. And, also, the factual relationship between work of art and artist, disseminated artistic reproductions.The analysis of the results made it possible to observe the following aspects. The authenticity of 17th-century Cusqueño art is manifested in the buildings of churches and peripheral parishes in popular neighborhoods. The same for painting and sculpture, whose principle of validity is demonstrated in the deformation of the Baroque style to introduce new aesthetic values, Inca ornaments, mixed faces, etc.

Keywords: José Uriel García, authenticity, art, artist, culture. 


\section{Contexto Cultural Artístico Cusqueño}

os pensadores cusqueños de las primeras décadas del siglo XX estaban convencidos de la influencia del medio ambiente en el proceso histórico. Ante ello "la importancia de la naturaleza andina y de su papel primordial y determinante apareciera incesantemente en todos los escritores indigenistas posteriores a 1909". (Tamayo, 1980, p.171). A partir de este concepto se fue articulando discursos de autenticidad regionalista; en el proclamaban la independencia de pensamiento cultural de la historiografía limeña.

En el caso del estudio del arte cusqueño, el medio más factible para difundir esta ideología fue por estudios históricos y arqueológicos sobre huacas Inkas, parroquias, iglesias, pintura virreinal, teatro, etc., propalados en: folletos, guías turísticas, artículos científicos, tesis y libros. Este proceso de formación fue impulsado. Primero, por las políticas educativas positivistas del rector Albert Giesecke1 (1910-1923) en la universidad San Antonio Abad, a partir de la Reforma universitaria (1909). En la cual, se formaron investigadores de arte cusqueño2, dinamizaron el conocimiento y escribieron la historiografía artística desde metodologías científicas.Cuya tarea fue, producir textos especializados sobre el arte cusqueño: José Uriel García, La ciudad de los incas, estudios arqueológicos (1922) y Guía histórico artístico del Cusco (1925); Felipe

1 La finalidad del rector Albert Giesecke fue construir la universidad San Antonio Abad como un laboratorio, para acercarse a la realidad regional cusqueña.

2 Debido a que muchos de los intelectuales formados bajo la política del Rector de la Universidad Nacional San Antonio Abad del Cusco Albert Giesecke, ingresaron a la carrera política. La década de 1930 suscitó avatares por los legisladores en el ámbito cultural-artístico cusqueño. Por lo tanto, desde su escaño lograron promulgar leyes culturales a favor del Cusco, entre ellos tenemos a Luis E. Valcárcel, José Gabriel Cosio Medina, José Uriel García, entre otros.
Cossío del Pomar, Pintura colonial (1930); Luis E. Valcárcel, Cuzco, Capital Arqueológica de Sudamérica (1934); y Humberto Vidal Unda, Hacia un Nuevo Arte Peruano (1938) Guía del Cusco para Turistas (1941).

Segundo, se editaron revistas académicas de carácter regionalista cuya, misión coadyuvó en establecer redes culturales entre investigadores coterráneos y de provincias limítrofes. Con la creación de la Revista Universitaria del Cuzco (1912), se difundieron tesis y artículos de investigación sobre el arte cusqueño; y contribuyeron sustancialmente en la revaloración artística de monumentos, retratos de próceres, edificaciones virreinales y pintura. Entre otros, tenemos las siguientes revistas: Kuntur, Wifala, Waman Poma, "Liwy, Kosko, con ilustraciones de xilograbados y las primeras reproducciones fotográficas de Martín Chambi. Kosko contó con la colaboración de Luis E. Valcárcel "cuyas ideas se difundirán por todo el altiplano y más al sur" (Kuón, 2009, p. 29).

Finalmente, la creación de organizaciones culturales influyó sustancialmente en crear la historia artística cusqueña a partir de estudios teórico/prácticos, que comprenden folklore, plástica y texto. Surgen a partir de la segunda década del siglo $X X$, inicialmente, mediante reuniones entre universitarios o personas interesadas en revalorar la historia cultural. El coleccionismo de pintura, escultura, indumentaria de danzas populares o recorridos por las huacas incas, fueron los más idóneos. Entre los cuales tenemos: La sociedad anónima de arte; la Sociedad de Bellas Artes; el Centro Nacional de Arte e Historia, y la Escuela de Artes y Oficios. E, instituciones culturalartísticas destinadas a propalar estudios académicos regionalistas: Centro nacional 
de arte e historia"3 institución pionera en enfatizar el pensamiento de intelectuales cusqueños. Y finalmente el Centro Qosqo de Arte Nativo4, fundado en 1924, tuvo como nombre primario Centro Musical Cuzco. Fue la primera institución cultural en tener trascendencia histórica en la ciudad, pues se dedicó a la promoción del arte folklórico en la ciudad y periferias.

\section{Autenticidad Cultural}

El concepto de autenticidad cultural, para José Uriel García, erociona a partir de la imposición del virreinato, mediante la síntesis ideológica; al margen de ser racial y sanguínea. Conformados en un crisol de identidades raciales, religiosas, artísticas, etc. En los que se interrelacionan factores trascendentales de clima y raza; categorías por el cual han impulsado en la construcción de hombres castizos, propios de cada región geográfica, del continente hispanoamericano. Al respecto, “erguidos sobre el lomo de ese noble bruto invasor nace la vida popular el gaucho argentino, el karabotas de Titikaka, el rastreador de las serranías del Perú, dramáticas figuras de los pueblos mestizos de América" (García, 1938, p. 140). En él se desarrollan aptitudes y

3 "El Centro Nacional de Arte e Historia conformado en 1916 con Ángel Vega Enríquez, los hermanos Cosio, José Uriel García y Rafael Aguilar. El punto central que este grupo quería destacar, era el regionalismo del arte en el Perú, en oposición al esnobismo de la intelectualidad limeña que señalaba que en nuestro país se carecía de temas locales para crear arte". (Kuón, 2009, p. 29).

4 Se formó el mismo año en que los artistas de la Misión Peruana de Arte Incaico, volviera de su exitosa gira por Bolivia, Argentina y Uruguay. "Un 6 de noviembr "El Centro Nacional de Arte e Historia conformado en 1916 con Ángel Vega Enríquez, los hermanos Cosio, José Uriel García y Rafael Aguilar. El punto central que este grupo quería destacar, era el regionalismo del arte en el Perú, en oposición al esnobismo de la intelectualidad limeña que señalaba que en nuestro país se carecía de temas locales para crear arte". (Kuón, 2009, p. 29). En "1924, reunidos ocho amigos artistas, en el interior de una cafetería o tetería llamada La Rotonda decidieron crear una agrupación de música y danza vernácula que bautizaron con el nombre de Centro Ccosco de Arte Nativo".(Kuón, 2009, p. 30). costumbres ligados generalmente al trabajo en obrajes virreinales, destinados a la manufactura de objetos para la vida cotidiana y artísticas.

En este sentido, la propuesta de autenticidad está asociada teóricamente al telurismo5 porque, a través de relaciones inmanentes entre raza y medio ambiente influyen en renovar ideologías culturales. Manifestándose como ansia o voluntad creadora que impulsa a la creación del regionalismo, a través de la creación artística. Al respecto "y -- ese sentimiento-- se nutre de los andes, emocionalmente, y del universo, idealmente. Nuestro nacionalismo artístico será acentuar la emoción y la idea de originalidad" (García, 1930, p.159). Al atribuirle cualidades trascendentales, por ser el primer motor que renueva, genera y dirige la vida cultural y biológica dentro del continente Hispanoamericano6.

Es importante enunciar que este proceso cultural, tiene como base material y geopolítica la sierra sur peruana; porque, a diferencia de la costa, esta no ha sufrido grandes avatares en su estructura social. El Cusco, otrora capital del imperio de los inkas, conservó influencias ideológicas y artísticas inkaicas, además de ser la caverna de la nacionalidad7 de pensadores, demiurgos y egregios, cuya labor fue transformar la cultura para hacerla mestiza. El Inca Garcilazo de la Vega, El lunarejo, Túpac Amaru, entre otros fueron los agentes del mestizaje cultural.

5 El telurismo de García se preocupa por demostrar la influencia de la tierra en el hombre. Asimismo según el autor, el arte es el resultado es esta infuencia.

6 De primera intención "queremos aclarar que al decir "cultura mestiza" no nos referimos precisamente a la producida por el descendiente fisiológico del español y de la india, sino al fruto del choque entre la cultura invasora, europea, y la autóctona, que implica al hombre social y no al individuo fisiológico". (García, 1950, p.64).

7 La caverna de la nacionalidad es el lugar de origen para el naci miento de egregios. La chichería recibe esta denominación a partir de 1930. Hasta 1925 utiliza el término para refirerirse al lugar de origen. 
Finalmente, el concepto de autenticidad cultural se consolida y desarrolla después de la conquista española. A través de la incorporación de elementos culturales materiales e ideológicos generando cambios paulatinos en la otrora sociedad inka, cuya trascendencia permitió la imposición de una estructura social de modelo occidental. Sin embargo, al cabo de unas décadas el pensamiento inkaico logro mimetizarse e imponerse en algunos aspectos ideológicos al hispano. Entre los más influyentes tenemos, por ejemplo, ante las distancias geográficas, a los antiguos peruanos que carecían de rueda y animales rápidos para transportarse; por lo cual, los españoles incluyeron el caballo y la rueda a nuestra geografía distante y chúcara, cambiando para siempre el orden natural de las cosas. Por lo que el autor expresa lo siguiente:

...la incursión de otros elementos que favorecieron el desarrollo del nuevo mundo la conquista de América es el proceso de amestizamiento que no ha terminado hasta ahora y que viene generando hondos problemas desde los biológicos hasta los sociales. (García, 1938, p.139).

\section{Autenticidad del Arte Cusqueño en el Siglo XVII}

La historiografía del arte peruano fue creado a inicios del siglo XX para justificar la existencia de nación a través del discurso artístico. Por lo que se le considera "conjuntamente al interés estatal de edificar peruanidad- naturalizar o inscribir objetos $\mathrm{u}$ obras especificas dentro de una narrativa histórica" (Marcos, 2020). La historiografía artística peruana del siglo XX inicia con la propuesta teórica de José de la Riva Agüero y Osma8 (1885-1944), con El Perú

8 "concibió el primero historicismo artístico nacional. Propiamente, suministró a la historia nacional el paradigma arte integrado (arte nacional). Una visión de armoniosa histórico y artístico (1921). Texto donde presenta la superposición de lo español sobre lo Inka. Y destaca el origen europeo del arte peruano y su labor educativa en el arte hispano. Asimismo, está concentrado en defender la hispanidad del arte peruano. Cuya ideología se extiende hasta la generación cusqueña de la Reforma universitaria, estudiado ampliamente por Yazmín López Lenci (1964). Por otro lado, Francisco Stastny (1933-2013), en Arte peruano (1976) menciona que los trabajos históricos sobre el arte peruano se "iniciaron en la década de 1920 con algunos esfuerzos aislados de U. García, J. Riva Agüero, F. Cossío del Pomar, L. E. Valcárcel". (1976, p.76). Sin embargo, la propuesta de García se diferencia de la de Riva Agüero, en el equilibrio entre identidades culturales.

Los ensayos de García pretenden partir hacia una narrativa que favorece enlaces históricos entre Inkas y virreinato, como sucesión natural en el tiempo, también aplicó retrospectivamente la noción moderna de arte a su historización de reliquias y monumentos. La pretensión teórica de García fue reconstruir la historia del Perú a partir del arte cusqueño9 por sus valores estéticos, proponiendo al mestizaje como restaurador e hilo conductor de la cultura peruana. Por ello, en sus ensayos_hasta1925_asume convergencias de identidades culturales plasmados en la plástica y presenta artistas de origen andino como demiurgos del nuevo arte. Sin embargo, este

cohesión artística de lo prehispánico con lo hispánico. Sin duda, Riva-Agüero fue alguien que creyó que una completa construcción de la historia pretérita peruana incluía tratar el tema de las artes (Riva-Agüero, 1937, tomo 1, p. 465). Estuvo convencido que muchas interrogantes históricas serían esclarecidas mediante las artes. Valoró las obras como hechos históricos con capacidad de revelar diferentes aspectos del Perú (culturales). En ese sentido, valoró las artes como documentos históricos". (Marcos, 2020).

9 "La propuesta de José de la Riva Agüero es lanzada a partir de la conciliación de la nacionalidad a partir de la integración del periodo colonial y del imperio incaico". (Lopez, 2004, p.698). 
proceso historiográfico inicia con los artistas hispanos y su labor de introducir técnicas y teorías, para más adelante institucionalizarlo mediante una "escuela de bellas artes que en el siglo XVII (y que) se estableció en Cuzco, fomento (ó)la producción de arte" (García, 1925, p.69). Dando origen a la estratificación social del mercado artístico, donde se establecieron dos categorías infranqueables, los artistas académicos y populares.Asimismo, para el autor, el arte cuzqueño está dominado por los artistas ibéricos, por introducir imágenes religiosas para su copia fiel, diseminados en corporaciones teológicas y comercio artístico. Cuya influencia mantiene atados a los artistas populares; sin embargo, estos buscan independizarce artísticamente en el clamor del pueblo mediante la deformación estilística de la ornamentación castellana.

Por ello, el derrotero de García, fue analizar holísticamente documentos, contratos de retablos, púlpitos, pintura, escultura, arquitectura y orfebrería. Para explicar los cambios de estilo sufrido en las artes a través de la historia cultural, en los que intervienen factores sociales diseminados en ideologías de corta y larga duración. Ante ello, existen agentes de renovación, por ejemplo el Obismo Manuel Mollinedo y Angulo (16261699) contribuyó en la renovación estilística impulsando la incorporción del Barroco en la arquitectura religiosa.

Este proceso se diseminó en parroquias periféricas de la ciudad, situados en barrios populares cusqueños, hogar de indios y mestizos. Importantes para demostrar la hipótesis, porque mantenian costumbres castizas adheridas a los inkas. Las parroquias deSan Cristobal, San Blas, Santa Ana y Recoleta cumplieron la misión de ser monumentos conmemorativos que participaron en la creación del regionalismo. Pues incorporan retratos de próceres de la independencia y nobles inkas, además de agregar ornamentos de ascendencia inkaika.

Las características de creación plástica, del artista mestizo, comprende un lenguaje de signos plásticos10 de imágenes castizas y mestizas a través de relexiones estéticas, cuya idea se manifesta desde un discurso ornamental. Ante ello, José Uriel García11, se dispone en hallar su origen: ¿Cómo se manifiesta históricamente la autenticidad del arte cusqueño en el siglo XVII? Pues bien, este inicia, timoratamente, después del terremoto; que destruyó gran parte de la ciudad y los suburbios (1650). En el periodo de reconstrucción, a cargo del obispo Manuel Mollinedo y Angulo12, mecenas de arte, y la participación importante de artistas mestizos e indígenas.

Se originó a partir de la deformación de ornamentos e imágenes religiosas del arte occidental, para introducir nuevos valores plásticos tomados del mundo cultural, de la región sur andina y cusqueña. Los que se conjugan con la inspiración del hombre

10 "Hay en la época llamada colonial formas nuevas originales por ambas culturas progenitoras que, en ciertos casos absorben completamente la una a la otra. La música incaica que es traducción emocional de los paisajes andinos, ejerce papel dominante en la expresión artística del nuevo espíritu- siendo para nosotros, si lames en ser sinceros, la única comprensiblelas artes decorativas hispánicas se sobreponen, en la nueva modalidad colonial, pero en manifestación distinta, nueva a lo que pudiera llamarse puramente español. El arte español viene a crearse también su ambiente andino". (García, 1924, p.35).

11 El material utilizado corresponde a la revisión de libros La ciudad de los Incas, estudios arqueológicos (1922), Guía Histórico- artística del Cusco, homenaje al centenario de Ayacucho (1925) y revistas: "El Cuzco incaico", 1921), "El Cuzco de la colonia" (1922) El movimiento filosófico contemporáneo y los ideales nacionales (1925- 1926). Todos publicados en Revista Universitaria del Cuzco.

12 "Esa primera ciudad duro algo más de un siglo, pues en 1650 acaeció un formidable terremoto que trajo por tierra a casi toda la totalidad de los monumentos públicos y edificios de la época anterior (...) Entonces viene la segunda época del arte colonial, se hace la reconstrucción del Cuzco y es el que perdura hasta hoy y el que ofrece interés arqueológico" (García, 1925, p.67). 
mestizo, porque crea el lenguaje de formas a partir de los modelos incaicos e hispanos. Ya que "la fusión objetivo-subjetiva que llama Guido, (...) da al nuevo tipo humano de la América Colonial una personalidad diversa a la de sus progenitores" (García, 1930, p. 147).

Finalmente, la concepción teórica de la autenticidad del arte cuzqueño (XVII) es desarrollada dentro de la expresión del estilo Barroco. Asimismo la última etapa de esta investigación desarrolla los elementos plásticos de arquitectura, pintura y escultura. Propuestospara su cabal comprensión.

\section{Arquitectura}

La arquitectura religiosa cusqueña situada, en los barrios periféricos, representa la máxima ascensióndeesteespírituauténtico, quegermina desde la conquista, y de manera esencial en parroquias y capillas . Representan valores estéticos de sabor castizo, los que se aprecian en fachadas y estructuras arquitectónicas. Estos se diseminan en ornamentos decorativos de motivos alusivos a flora, fauna, elementos incaicos y antropomórficos. Este complejo lenguaje visual propone las ansias de la independencia artística de los diseños plásticos occidentales. Sin embargo, no sólo se situaron en la periféria, sino también calaron tímidamente en instituciones oficiales, como en el caso del "(hoy local de la universidad cusqueña) donde se ostentan dos rostros indígenas, de estilización mitológica, dos rostros lamentablemente náufragos entre la opulencia decorativa del dominio español" (García, 2015, p.168).

Sin embargo, el concepto de autenticidad lo determina la emoción vernácula del alarife mestizo mediante el cual se reproducen templos ejemplares. Las iglesias de: Santa
Anta, San Blas, San Cristobal, San Sebastián, San Francisco y Santo Domingo. Analizados en tres aspecto, a continuación:

Primero, a través de la incursión timorata de elementos arquitectonicos nativos a las estructuras religiosas de ideología Ibérica. Las que fueron construidas sobre la base de huacas inkas, o en barrios indígenas. En la iglesia de Santo Domingo conviven torreones inkas con estructuras barrocas. Al respecto "existen otras ruinas correspondientes a las divinidades Rayo, Trueno i Arco iris i la sala descubierta que debió ser seguramente sala de sacrificios" (García, 1922 p.192). En otras, es por materiales usados por los inkas: "el templo es de tres naves. Con material de barro, en inaudito contraste con la solidez i el gran estilo de la fachada" (García, 1922, p. 236).

El siguiente aspecto, comprende la inclusión de elementos arquitectónicos de origen andino, análogos con la naturaleza $\mathrm{u}$ ornamentos inkas, diseminados en parroquias incrustadas en pendientes o cuestas. Por ejemplo:

El caso de la iglesia de San Cristóbal, es utilizado por el autor para defender su ideología, mediante la comparación de que las "finas copas de los eucaliptos parecen ojivales cresterías de una gigantesca construcción" (García, 1922, p.220).

La importancia de la iglesia de San Sebastián (Fig. 1), es por conjugar la solidez del estilo barroco con motivos geométricos de flora $y$ fauna, manifestándose la perfecta convivencia de identidades. Al respecto "en la evolución artística de la arquitectura en el Cuzco, San Sebastián representa la última etapa. El sobrio barroco de la Compañía se resuelve aquí en una brillantez decadente. Maravilla su riqueza decorativa" (García, 1922, p. 233). 
Finalmente, el barrio de San Blas, por su callejas angostas y oblongas, es hogar de alarifes mestizos, cuya parroquia se mimetiza con la plaza y le da sabor nacional. También, por motivos geométricos que muestran arabescos de flora "al fondo, las sinuosas crestas andinas que se extienden largamente hasta confundirse con las altas cumbres del Ausangate" (García, 1922, p.225).

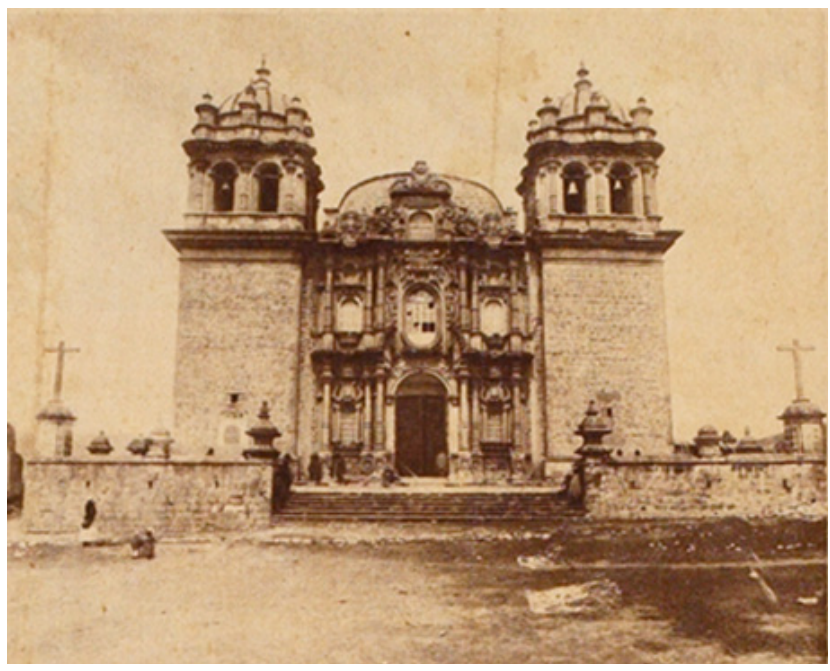

Figura 1. Iglesia de San Sebastián en los suburbios del Cuzco. Fuente: diario La Prensa de Buenos Aires.

\section{Pintura}

La producción pictórica en el virreinato se desarrolla a partir de la demanda mercantilista de las ordenes religiosas y feligreses. En consecuencia, las representaciones muestran un lenguaje plagado de iconografía católica, difundido en: lienzos, estampas, libros etc. Para narrar el origen de la humanidad, y su desenlace. Al respecto, "sucede una larga época de paz imperturbable de lánguida monotonía i de intenso fervor religioso, a cuyo impulso surge la obra creadora, concretada principalmente en el arte colonial". (García, 1922, p.106).
La función de los artistas europeos, criollos nativos y mestizos "altareros", es ilustrar pasajes de la biblia, vida de santos, ángeles y vírgenes. $\mathrm{Y}$, a partir de estos, se construye la historia visual cuzqueña, porque difunden ideologías y políticas del virreinato.Donde incluyen, retratos, tradiciones populares, fiestas religiosas, héroes, próceres, santos, entre otros.

En las primeras décadas de fundación del virreinato, el desempeño de los artistas nativos y mestizos es considerado por el autor, en ser copistas y repetidores de pinturas ibéricas. Porque, considera que adolecen de rebeldía y albedrío, por los siguientes aspectos. El carecer de técnica y formación artística determina substancialmente el valor artístico, el "pincel criollo con faltas graves de técnica; pero son lienzos de inmenso valor documental, cuadros costumbristas de la vida cuzqueña de fines del siglo XVII a esta época corresponden estos documentos pictóricos" (García, 1922, p. 214). Aunque su valor testimonial es incuestionable, por la riqueza decorativa. Asimismo, su verdadero propósito fue la difusión ideológica para satisfacer al pueblo analfabeto. Al respecto, el autor dispone que:

... los pintores indigenas juegan un papel enorme en la producción artística de la Colonia, mantienen la tradición del estilo nativo, pero emplean la técnica revelada por los maestros castellanos. No pudieron amplificar su visión hacia la profundidad o tercera dimensión de las cosas. (García, 1924, pp. 36-37).

Sin embargo, la rebeldía pictórica se manifiesta a través de tres razones fundamentales. Primero, el uso de una técnica huérfana en destrezas compositivas y falta de perspectiva de los pintores mestizos, coadyuvó a representar un estilo ingenuo, considerado como inicio del nacionalismo en la pintura. Por 
consiguiente "Los muros de las galerías de los bajos están historiadas con pinturas grotescas que representan la vida de san Francisco, creaciones de algún pincel torpe" (García, 1922, p.187).

Segundo, los retratos realistas de autoridades pretéritas, inkas y mestizas, fueron incluidos en las capillas para ser homologados con lienzos de santos. Con la finalidad de enaltecer la imagen de hombres mestizos y ser considerados fundadores de la nación peruana. Por ello, "en la capilla, fuera de algunos lienzos hai uno donde esta el retrato del prócer de la independencia Agustín Chacón y Becerra" (García, 1922, p.115). También, en la capilla de Santa Ana "los cuadros que decoran las enjutas de las bóvedas altas o ventanales, de donde se ven retratos de nobles incas del coloniaje, a cuya devoción se ejecutaron son de concepción amestizada" (García, 1922, p.85).

Finalmente, la representación de individuos anónimos de caráterísticas raciales mestizas son ataviados con indumentarias inkas, para

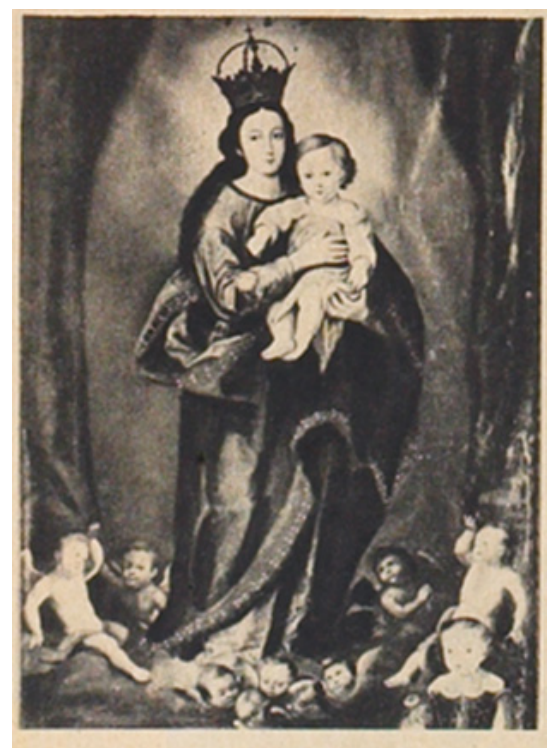

Figura 2. Cuadro de pincel mestizo, imitación occidental (Catedral del Cuzco). Fuente: diario La Prensa de Buenos Aires servir de modelos ideológicos. En el que se anuncia el nacimiento del nacionalismo a partir de sincretismo en la plástica "al pie de este lienzo hai un grupo de mujeres del pueblo contemplando las rarezas del altar, todas llevan en la cabeza chchullus en forma de turbante las llicllas o rebezas con picos tipis de plata" (García, 1922, p .220). Y propone la unión entre el pretérito y el presente "antigua capilla del baptisterio que alude a la descensión de María a SUNTURHUASI. Allí se ven los retratos de incas y koyas ataviados con trajes coloniales" (García, 1925, p.85).

\section{EsCULTURA}

Los artistas escultóricos mestizos, a difrencia de pintores y arquitectos no han sido estudiados a profundidad hasta 1925. Sin embargo, existen pocos ejemplos de este problema.

El caso sui generis de Juan Melchor, en la capilla Almudena, siendo una de las más notables esculturas en bulto entre las de su indole del Cusco virreinal. Porque utiliza su destreza artística para retratar a una mujer cusqueña.

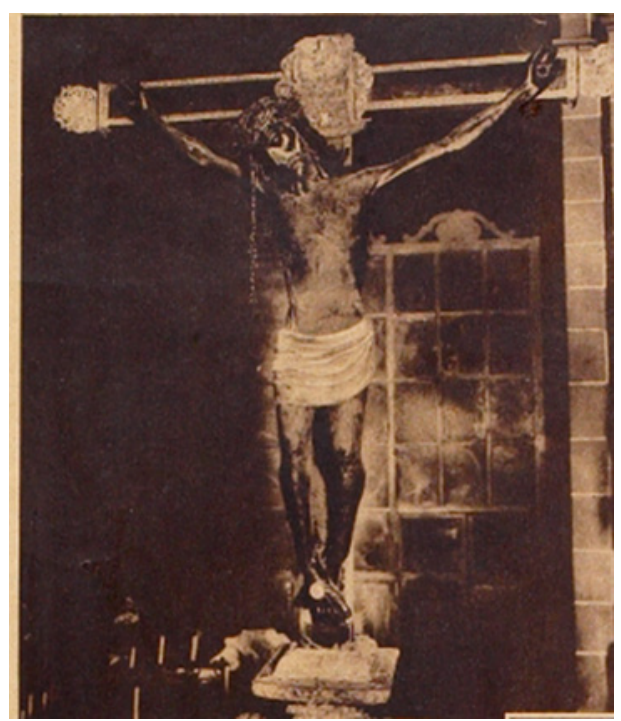

Figura 3. El Señor de los Temblores, en la Catedral del Cuzco. Fuente: diario La Prensa de Buenos Aires. 
$\mathrm{O}$, la escultura que representa a la imagen de Santo Domingo de Guzmán como acredita la inscripción que se encuentra en el plinto de cada obra.

Para finalizar, en el caso de la fachada de la universidad se observa que "sobre el arco de la entrada hay dos elementos característicos decorativos: dos rostros de indios estilizados, que denotan la influencia del arte nativo en la ornamentación arquitectónica" (García, 1925, p.92). Por lo menos, estos referentes dejan abiertas las posibilidades de investigar el tema con pasión nacionalista.

\section{REFERENCIAS BibLIOGRÁFICAS}

1. Caparó, M. (2019) José Uriel García: El discurso del arte mestizo como proyecto de identidad nacional en los artículos publicados en el diario La Prensa de Buenos Aires (1931-1939). (Tesis de Licenciatura) Universidad Nacional Mayor de San Marcos.

2. García, J. (1921) El Cuzco incaico, en Revista Universitaria. Cusco: $\mathrm{N}^{\circ} 35$ Agosto, p. 108-122.

3. García, J. (1922) La ciudad de los incas, estudios arqueológicos. Cusco, Perú, editorial H. G. Rosas Sucesores.

4. García, J. (1924) El Cuzco de la colonia en Revista Universitaria. Cusco: $\mathrm{N}^{\circ} 44-452^{\circ}$ y $3^{\circ}$ trimestres, p. 30-42.

5. García, J. (1925) Guía- histórico artística del Cusco, Lima: Editorial Lima Garcilaso.

6. García, J. (1925- 1926) El movimiento filosófico contemporáneo y los ideales nacionales. En Revista Universitaria. Cusco: $\mathrm{N}^{\circ}$ 49-50 $4^{\circ}$ trimestre de $19251^{\circ}$ trimestre de 1926, p. 25-37.
7. García, J. (1930) El nuevo Indio. Cusco: Editorial H. G. Rosas Sucesores.

8. Guido, A. (1925) Fusión hispano-indígena en la arquitectura colonial. Rosario Argentina. Editorial: La Casa del libro.

9. Kuón, E., Gutierréz, R., Gutierréz, R. \& Viñuales, G. (2009) Cuzco Buenos Aires. Ruta de la intelectualidad americana (19001950) Lima. Editorial Fondo Editorial Universidad San Martín de Porres.

10. López, Y. (2004) Cusco la paqarina moderna: cartografía de una modernidad e identidades en los andes peruanos (1930-1935). Lima: Editorial UNMSM fondo editorial CONCYTEC.

11. Marcos, M. (2020) LA HISTORIOGRAFÍA ARTÍSTICANACIONAL EN LA UNMSM (ENSAYO). Revista digital Apostillas, Grupo de Estudios de Historia del siglo XX.

12. Rojas, R. (1922) La Argentinidad. Editorial: Librería de la facultad Juan Roldán.

13. Rojas, R. (1924) Eurindia: Ensayo de estética fundado en la experiencia histórica de las culturas americanas. Editorial: Librería de la facultad Juan Roldán.

14. Stastny, F. (1976) Arte peruano: Investigaciones y difusión 19791976. Revista Cuadrenos del consejo nacional de la universidad peruana. $\mathrm{N}^{\circ} 20-21$, enero-junio 1976, p.70-82.

15. Tamayo J. (1980) Historia del indigenismo cusqueño. Siglos XVIXX) Lima: Editorial Instituto Nacional de Cultura.

\section{CORRESPONDENCIA}

Marco Antonio Caparó Aragón

artemarco285@gmail.com

Fecha de recepción: 19-10-2020.

Fecha de aceptación: 11-01-21.

Conflicto de interés: ninguno, según el autor.

Financiamiento: por el autor. 